\title{
Comparative Study of Two Methods of Estimating Sinoatrial Conduction Time in Patients with Abnormal Sinus Node Function
}

\author{
Daisuke Inoue, M.D., Hiroshi Katsume, M.D., \\ Haruo Matsukubo, M.D., Keizo Furukawa, M.D., \\ Yukio Torir, M.D., Toshimitsu Watanabe, M.D., \\ and Hamao IJichi, M.D.
}

\section{SUMMARY}

This study compared a new method to estimate sinoatrial conduction time (SACT) using continuous atrial pacing proposed by Narula et al with the widely used method using premature atrial stimulation originally proposed by Strauss et al. The estimated SACTs by the two methods were obtained in 19 patients with normal sinus node (SN) function (Group A) and 8 patients with abnormal SN function (Group B).

Estimate of the SACT by the Narula method was taken as the difference between the first atrial return cycle after pacing and the basic sinus cycle length (BSCL). The Narula method was performed for a train of 8 consecutive beats at three different pacing cycle length (PCL); PCL (1) $\geqq$ BSCL-50, PCL (2) $\geqq$ BSCL- 100 and PCL ( 3$) \geqq B S C L-150$ msec.

In group A, the estimated SACTs by the Strauss method was $185 \pm 49.3$ msec, meanwhile the SACTs by the Narula method were $148 \pm 80.7$ at PCL (1), $181 \pm 58.7$ at PCL (2) and $212 \pm 84.5 \mathrm{msec}$ at PCL (3) (mean \pm SD); the coefficient of correlation between the Strauss method and the Narula method were $0.58,0.84$, and 0.67 , respectively.

On the other hand, in group B, atrial return cycles by the Narula method were abnormally prolonged (over $215 \mathrm{msec}$ ) in 5 of 8 cases $(63 \%)$ even at PCL (2) and in all of the cases $(100 \%)$ at PCL (3). By the Strauss method, SACTs in 6 of 8 cases could not be defined; however it was possible to assess the type of SN dysfunc-

From the Second Department of Internal Medicine, Kyoto Prefectural University of Medicine, Kawaramachi-Hirokoji, Kamikyo-ku, Kyoto 602, Japan.

Address for reprint: Daisuke Inoue, M.D., Second Department of Internal Medicine, Kyoto Prefectural University of Medicine, Kawaramachi-Hirokoji, Kamikyo-ku, Kyoto 602, Japan.

Present address: Daisuke Inoue, M.D., Department of Pharmacology, University of Connecticut Health Center, Farmington, Connecticut 06032, U.S.A.

Received for publication August 19, 1980.

Manuscript revised March 3 and April 20, 1981. 
tion by the pattern of the atrial return cycles.

In conclusion, the estimated SACT by the Narula method at PCL (2) corresponded well with the SACT by the Strauss method in patients with normal SN function. However, it was difficult to determine SACT in patients with Sick Sinus Syndrome by both methods.

\section{Additional Indexing Words :}

Strauss method Narula method Sick sinus syndrome

CINOATRIAL conduction time (SACT) has been considered to be one $D$ of the important factors in analysing sinus node function. However, the method has not yet been confirmed by recording the electrical activity of human sinus node directly. Further development is necessary for confirmation by the direct recording technique, although some investigators reported that they could record the electrical potentials of the sinus node in man using an ordinary bipolar electrode catheter positioned near the sinus node and high gain d.c. amplification with $0.5-30 \mathrm{~Hz}$ filter settings. ${ }^{1)-4)}$

At the present time, to estimate the SACT in man, there have been two methods introduced. The first was proposed by Strauss et al in 1973.5) Using premature atrial stimulation (PAS) according to this method, the SACT is indirectly estimated by subtracting basic sinus cycle length (BSCL) just before the PAS from atrial return cycle immediately after the PAS. This method is used in many cathetcrization laboratories, however many experimental and clinical data have shown that it is burdened by unsolved methodological problems. ${ }^{6), 7)}$ A new and simpler method to estimate SACT using continuous atrial pacing (CAP) was recently proposed by Narula et al. ${ }^{8}$ They considered their new method to be more efficient than the Strauss method, because not only did it prove to be simpler and quicker than the earlier method, but the results from both methods also corresponded very well.

However, their data showed that the shorter the atrial pacing cycle length, the longer the post pacing first sinus cycle interval, even if atrial pacing was performed at a slightly faster rate than the control sinus rate. Then it should be considered that both the uncertainty of sinus node capture at slower pacing rate and the overdrive suppression of the sinus node at faster pacing rate might occur.

We studied the effect of pacing rate change on the SACTs estimated by the same method as proposed by Narula et al at three kinds of slightly shorter pacing cycle length than BSCL, and compared the SACTs by the 
Narula method with those obtained by the Strauss method in patients with normal and abnormal sinus node function.

\section{Methods and Materials}

Twenty-seven patients were studied in the nonsedated post absorptive state after having given written informed consent. They were admitted to the hospital for evaluation of cardiac arrhythmias and other cardiac diseases. The patients were divided into two groups on the basis of data derived from the sinus node function studies (Table I). Group A consisted of 19 patients (mean age 51 years; 13 males, 6 females) with normal sinus node function. Group B consisted of 8 patients (mean age 54 years; 3 males, 5 females) with clinical features of sinus node dysfunction. The patients were symptomatic with dizziness or syncope and were documented to be abnormal either on EGG (persistent or intermittent sinus bradycardia, spontaneous sinoatrial (SA) block or sinus arrest) or on electrophysiological study of sinus node function (corrected sinus node recovery time (CSRT) $\geqq 525 \mathrm{msec}$ ).

A quadripolar catheter with a distance of $1 \mathrm{~cm}$ between each electrode

Table I. Clinical Diagnosis and Flectrophysiological Data in 27 Patients

\begin{tabular}{|c|c|c|c|c|c|c|c|c|c|c|c|}
\hline \multicolumn{2}{|c|}{ Cases } & \multirow{2}{*}{$\frac{\text { ECG, Clinical DX. }}{\text { rmal sinus Node Functior }}$} & \multicolumn{2}{|c|}{ Strauss } & \multicolumn{2}{|c|}{$\begin{array}{l}\text { Narula (PCL }(1)) \\
\text { BSCL(1) SACT }\end{array}$} & \multicolumn{2}{|c|}{$\begin{array}{l}\text { Narula (PCL (2)) } \\
\operatorname{BSCL}(2) \operatorname{SACT}\end{array}$} & \multicolumn{2}{|c|}{$\begin{array}{l}\text { Narula (PCL (3)) } \\
\text { BSCL(3) SACT }\end{array}$} & \multirow[t]{2}{*}{$\begin{array}{l}\operatorname{csRT} \\
(\max )\end{array}$} \\
\hline \multirow[b]{2}{*}{$\begin{array}{l}\text { 1. J.K. } \\
\text { 2. U.H. } \\
\text { 3. A.M. } \\
\text { 4. T.T. } \\
\text { S. S.M. } \\
\text { 6. E.Y. } \\
\text { 7. C.Y. } \\
\text { O. Y.O. } \\
\text { 9. H.M. } \\
10 . \text { E.Y. } \\
11 . \text { S.T. } \\
12 . \text { H.H. } \\
13 . \text { H.N. } \\
14 . \text { S.N. } \\
15 . \text { T.A. } \\
16 . \text { K.T. } \\
17 . \text { H.M. } \\
18 . \text { K.H. } \\
19 . \text { Y.O. }\end{array}$} & $\mathrm{A} 1$ & & i) & & & & & & & & \\
\hline & 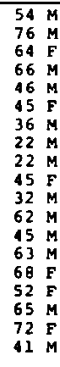 & $\begin{array}{l}\text { LAH, Angina Pectoris } \\
3^{\circ} \text { AV Block } \\
2^{\circ}-3^{\circ} \text { AV Block } \\
\text { VPCS, WPW (A) } \\
\text { VPCs } \\
\text { PSVT, WPW (C) } \\
\text { AV dissociation } \\
1^{\circ} \text { AV Block } \\
2^{\circ} \text { AV Block } \\
\text { PSVT, WPW(C) } \\
\text { PSVT } \\
\text { APCs } \\
\text { Angina Pectoris } \\
\text { CRBBB, LAH, int. } 3^{\circ} \text { AVBlock } \\
\text { PSVT } \\
\text { PSVT, WPW(C) } \\
\text { PSVT } \\
\text { PSVT } \\
\text { AErial septal defect }\end{array}$ & $\begin{array}{r}839 \\
628 \\
945 \\
950 \\
754 \\
571 \\
848 \\
840 \\
1045 \\
667 \\
951 \\
820 \\
900 \\
869 \\
805 \\
764 \\
874 \\
778 \\
847\end{array}$ & $\begin{array}{l}181 \\
189 \\
106 \\
202 \\
204 \\
12 B \\
\text { N.D. } \\
203 \\
\text { N.D. } \\
159 \\
153 \\
204 \\
298 \\
161 \\
225 \\
248 \\
217 \\
90 \\
172\end{array}$ & $\begin{array}{r}835 \\
630 \\
1003 \\
953 \\
730 \\
573 \\
950 \\
804 \\
1073 \\
673 \\
935 \\
790 \\
908 \\
894 \\
810 \\
762 \\
940 \\
773 \\
862\end{array}$ & $\begin{array}{r}173 \\
85 \\
38 \\
85 \\
50 \\
58 \\
100 \\
261 \\
178 \\
93 \\
225 \\
223 \\
346 \\
130 \\
108 \\
209 \\
223 \\
139 \\
82\end{array}$ & $\begin{array}{r}830 \\
630 \\
925 \\
944 \\
720 \\
570 \\
890 \\
888 \\
1090 \\
665 \\
925 \\
790 \\
892 \\
1003 \\
848 \\
776 \\
942 \\
760 \\
832\end{array}$ & $\begin{array}{l}135 \\
133 \\
105 \\
157 \\
170 \\
90 \\
250 \\
245 \\
150 \\
140 \\
205 \\
210 \\
306 \\
158 \\
238 \\
273 \\
208 \\
128 \\
136\end{array}$ & $\begin{array}{l}953 \\
\\
578 \\
\\
883 \\
965 \\
658 \\
864 \\
843 \\
878 \\
903 \\
855 \\
803 \\
906 \\
770 \\
851\end{array}$ & $\begin{array}{r}138 \\
85 \\
233 \\
140 \\
153 \\
365 \\
243 \\
361 \\
138 \\
258 \\
321 \\
245 \\
245 \\
207\end{array}$ & $\begin{array}{r}330 \\
378 \\
355 \\
170 \\
240 \\
80 \\
246 \\
380 \\
405 \\
150 \\
250 \\
330 \\
400 \\
409 \\
330 \\
485 \\
396 \\
172 \\
490\end{array}$ \\
\hline \multicolumn{2}{|c|}{$\begin{array}{r}\text { Mean } 51.4 \\
\text { SD } \leq 15.7 \\
\end{array}$} & & $\begin{array}{r}826.1 \\
\pm 113.6 \\
\end{array}$ & $\begin{array}{r}184.7 \\
\pm 49.5 \\
\end{array}$ & $\begin{array}{r}836.7 \\
\pm 126.3 \\
\end{array}$ & $\begin{array}{r}147.6 \\
\pm 80.7 \\
\end{array}$ & $\begin{array}{r}837.9 \\
+127.2 \\
\end{array}$ & $\begin{array}{r}180.9 \\
558.7 \\
\end{array}$ & $\begin{array}{r}840.0 \\
2100.5 \\
\end{array}$ & $\begin{array}{r}211.9 \\
\times 84.5 \\
\end{array}$ & $\begin{array}{r}331.4 \\
+111.7 \\
\end{array}$ \\
\hline \multicolumn{12}{|c|}{ Group B ( Sinus Node Dysfunction) } \\
\hline $\begin{array}{l}20 \cdot I \cdot U . \\
21 \cdot \text { Y.T. } \\
22 \cdot \text { H.T. } \\
23 \cdot \text { T.M. } \\
24 \cdot \text { E.H. } \\
25 \cdot \text { K.U. } \\
26 \cdot \text { K.F. } \\
27 . \text { S.M. }\end{array}$ & $\begin{array}{ll}48 & F \\
47 & M \\
74 & M \\
20 & F \\
71 & F \\
53 & M \\
66 & F \\
50 & F\end{array}$ & $\begin{array}{l}\text { SA Block } \\
\text { SA Block } \\
\text { SA Block } \\
\text { SA Block } \\
\text { SA Block } \\
\text { Brady-Tachy Syndrome } \\
\text { Brady-Tachy Syndrome } \\
\text { Sinus Bradycardia }\end{array}$ & $\begin{array}{l}1034 \\
1333 \\
1402 \\
690 \\
712 \\
1911 \\
1082 \\
1134\end{array}$ & $\begin{array}{l}\text { N.D. } \\
\text { N.D. } \\
\text { N.D. } \\
\text { N.D. } \\
\text { N.D. } \\
448 \\
\text { N.D. } \\
169\end{array}$ & $\begin{array}{r}1040 \\
1330 \\
1505 \\
\\
710 \\
1290 \\
1080 \\
1150\end{array}$ & $\begin{array}{c}766 \\
(4970) \\
545 \\
80 \\
198 \\
30 \\
159\end{array}$ & $\begin{array}{r}1023 \\
1428 \\
620 \\
691 \\
1218 \\
1145 \\
1160\end{array}$ & $\begin{array}{l}554 \\
495 \\
940 \\
992 \\
298 \\
215 \\
119\end{array}$ & $\begin{array}{r}1113 \\
1330 \\
1433 \\
686 \\
572 \\
1228 \\
1140 \\
1145\end{array}$ & $\begin{array}{r}425 \\
(4250) \\
498 \\
706 \\
1208 \\
423 \\
313 \\
238\end{array}$ & $\begin{array}{r}881 \\
8367 \\
1400 \\
1050 \\
1528 \\
579 \\
913 \\
401\end{array}$ \\
\hline $\begin{array}{l}\text { Mean } \\
\text { SD } \pm\end{array}$ & $\begin{array}{r}53.6 \\
\pm 16.2 \\
\end{array}$ & & $\begin{array}{r}1162.3 \\
\pm 370.3 \\
\end{array}$ & $\begin{array}{r}308.5 \\
\pm 139.5 \\
\end{array}$ & $\begin{array}{l}1150.7 \\
\pm 232.1\end{array}$ & $\begin{array}{r}296.3 \\
\pm 267.3\end{array}$ & $\begin{array}{r}1040.7 \\
+268.9\end{array}$ & $\begin{array}{r}516.1 \\
\pm 317.1\end{array}$ & $\begin{array}{l}1080.9 \\
\pm 280.9\end{array}$ & $\begin{array}{r}544.4 \\
9 \pm 303.6\end{array}$ & $\begin{array}{r}1889.9 \\
\pm 2473.2\end{array}$ \\
\hline
\end{tabular}

$\mathrm{BSCL}=$ basic sinus cycle length; SACT = sinoatrial conduction time; $\mathrm{PCL}=$ pacing cycle length ; $\mathrm{CSRT}=$ corrected sinus node recovery time; $\mathrm{APC}=$ atrial premature complexes; $\mathrm{AV}=$ atrioventricular; $\mathrm{VPC}=$ ventricular premature complexes; WPW $=$ Wolff-Parkinson-White syndrome (A, B, or C type); PSVT=paroxysmal supraventricular tachycardia ; CRBBB=complete right bundle branch block; $\mathrm{LAH}=$ left anterior hemiblock; int.=intermittent; $\mathrm{SA}=$ sinoatrial ; Brady-Tachy = bradycardia and tachycardia; N.D.=non definable. 
was introduced into the right or left femoral vein percutaneously and the catheter was positioned under fluoroscopic control near the junction of superior vena cava and right atrium. The distal pair of electrodes was used for high right atrial (HRA) potential recording, and the proximal pair was used for HRA stimulation. The HRA was stimulated with a programmable stimulator (Nihon Kohden, Cardiac Stimulator SEG-1102) delivering rectangular stimuli $2 \mathrm{msec}$ in duration and twice the diastolic threshold.

Using a coventional method, ${ }^{\text {9) }}$ a bipolar or tripolar electrode catheter was introduced using the same technique as above to obtain His bundle electrogram (HBE) recording. Bipolar electrogram displayed at frequency settings of $30-1,000 \mathrm{~Hz}$ were recorded from $\mathrm{HRA}$ and $\mathrm{HB}$ regions simultaneously with two or three standard ECG leads (II or $\mathrm{V}_{1}$ ). All recordings were made on a multichannel ink jet paper recorder (Mingograf 800 ) at paper speeds of $100 \mathrm{~mm} / \mathrm{sec}$.

The overdrive suppression test with rapid atrial pacing was used to obtain the sinus node recovery time (SRT). Atrial pacing rates of $80-200 / \mathrm{min}$ (at 20 beats/min increment) for $30 \mathrm{sec}$ was used. The BSCL was subtracted from the SRT, and the difference was then expressed as the corrected sinus node recovery time (GSRT).

\section{Strauss method:}

The SACT by the Strauss method was estimated according to their recent paper ${ }^{10)}$ as follows: (1) $A_{1} A_{1}=$ the spontaneous sinus cycle (the interval between the last two spontaneous sinus $P$ waves that preceded the PAS induced HRA ( $A_{2}$ ) activity), (2) $A_{1} A_{2}=$ the test cycle (the coupling interval between the last $A_{1}$ and the stimulus induced $A_{2}$ ), (3) $A_{2} A_{3}=$ the atrial return cycle (the interval between the $A_{2}$ and the following $\operatorname{HRA}\left(A_{3}\right)$ activity), and (4) $\mathrm{A}_{3} \mathrm{~A}_{4}=$ the post atrial return cycle (the spontaneous sinus cycle immediately following the return cycle). Premature atrial stimuli were given late in the atrial diastole after every eighth spontaneous sinus cycle. The coupling intervals $\left(A_{1} A_{2}\right)$ were shortened (in decrements of $10-20 \mathrm{msec}$ ) until the effective refractory periods of the right atrium was encountered.

In each patient, the normalized test cycle $\left(A_{1} A_{2} / A_{1} A_{1} \times 100\right)$ was plotted on the abscissa, and the normalized atrial return cycle and post atrial return cycle, if necessary, on the ordinate.

Zone $I$ and Zone II were defined as follows: Zone $I$ is the non reset zone (Compensatory zone), that is $A_{2} A_{3}+A_{1} A_{2}=2 A_{1} A_{1}$, and Zone II is the reset zone, that is $A_{2} A_{3}+A_{1} A_{2}<2 A_{1} A_{1}$. The transition from Zone $I$ to Zone II was easily identified in 17 of the 19 patients in group A (Zone II could not be defined clearly in 2 patients, case nos. 7 and 9 ; because they showed dis- 
persed atrial return cycles due to sinus arrhythmias). SACT was estimated as the sum total of antegrade and retrograde conduction time of the sinus node, that is $S A C T=A_{2} A_{3}-A_{1} A_{1}$. For the estimation of SACT, the responses occuring within the $35-65 \%$ boundary of the plateau zone were averaged.

\section{Narula method:}

The estimation of the SACT by the Narula method was originally described as follows ${ }^{8}$ : Atrial pacing was given to all patients at a rate slightly faster ( $\leqq 10$ beats/min) than the basic sinus rhythm for a train of eight consecutive beats. The SACT by this method was calculated by subtracting the mean sinus cycle length (mean of BSCL before the pacing) from the interval between the last paced atrial electrogram and the atrial electrogram of the first escaped sinus node cycle. The patients with abnormal sinus node function who have rather slower sinus cycle length were among the subjects in this study. It is sometimes experienced that slightly faster atrial pacing than the BSCL induced abnormally prolonged SRT in such patients. These results suggest that the automaticity is depressed or that the retrograde conduction time is prolonged.

The SACT by the Narula method is dependent on the PCL as Grant et al showed experimentally ${ }^{11)}$ that $\mathrm{PCL} \leqq 5$ beats/min faster than the spontaneous sinus rate may not capture the sinus node consistently, and they proposed numbers of pacing cycles required for sinus node capture.

In this study, we wished to assess the effect of pacing rate on the SACTs and to obtain SACT in a narrower range of PCLs ( $\leqq 10$ beats/min). Therefore, three PCLs were tried as follows: PCL (1) was the rate within $50 \mathrm{msec}$ shorter than BSCL. PCL (2) and PCL (3) were the rates 50-100 msec, and 100-150 msec shorter than BSCL, respectively. The three preceding BSCLs just before each pacing was calculated as the mean BSCL for the estimation of the SACT at the PCL. The procedure was repeated after every eight to ten spontaneous sinus cycles for a total of 3-5 times per patients at each pacing cycle.

Student's t-test for paired data was used for statistical evaluation.

\section{Results}

There was no significant difference in the BSCLs during the estimation of the SACTs by the Strauss method and the Narula method. Fig. 1 shows a typical case (no. 15, 68-year-old, female, PSVT); the estimated SACTs by both methods corresponded well. The SACT by the Strauss method was calculated as $225 \mathrm{msec}$ in the upper panel; in this case Zone II was 


\section{PAS Mothod (Strouss)}

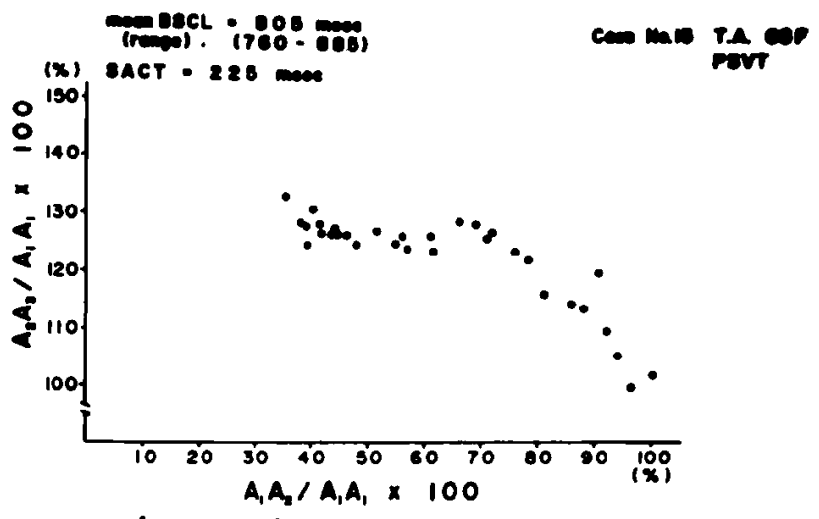

CAP Mothod (Norula)

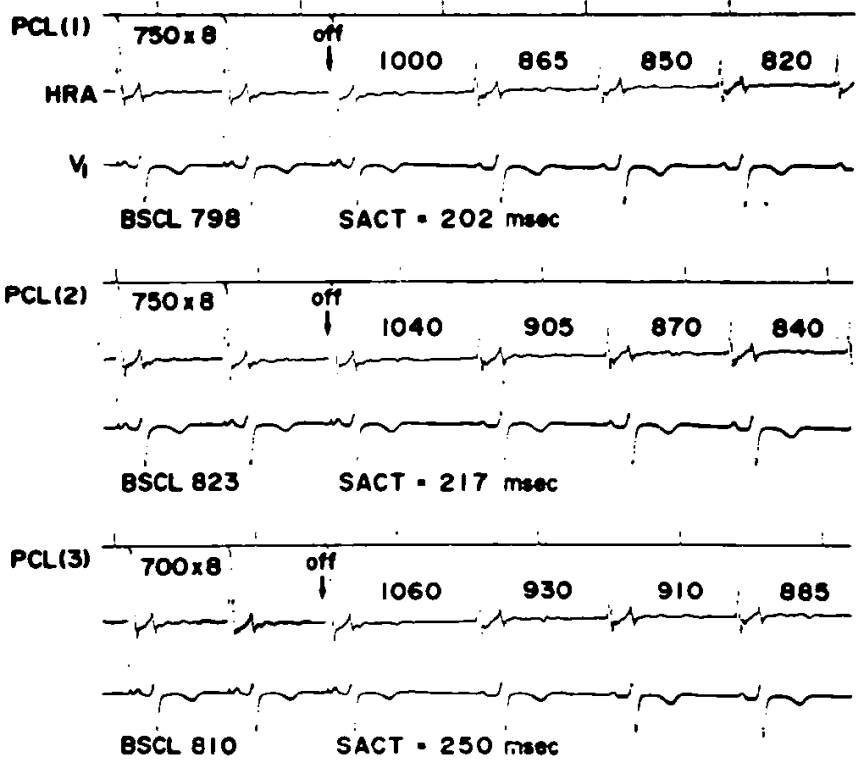

Fig. 1. A typical example of the estimation of sinoatrial conduction time both by the Strauss method and by the Narula method. The upper panel shows the Strauss method by which SACT $=225 \mathrm{msec}$ is estimated. The lower panel shows the Narula method by three pacing cycle lengths (PCL).

clcarly defined. The SACT by the Narula method was estimated as follows: $1000 \mathrm{msec}-798 \mathrm{msec}=202 \mathrm{msec}$ at $\mathrm{PCL}(1), 1040 \mathrm{msec}-823 \mathrm{msec}=217 \mathrm{msec}$ at $\mathrm{PCL}(2)$, and $1060 \mathrm{msec}-810 \mathrm{msec}=250 \mathrm{msec}$ at $\mathrm{PCL}(3)$, respectively. The SACT at PCL(2) corresponded well with the SACT by the Strauss method, although a slight increase of the SACTs accompanied the decrease of PCL. As it has been mentioned before, the same PCL $750 \mathrm{msec}$ was classified in PCL(1) and PCL(2) because of the difference of BSCLs at each 

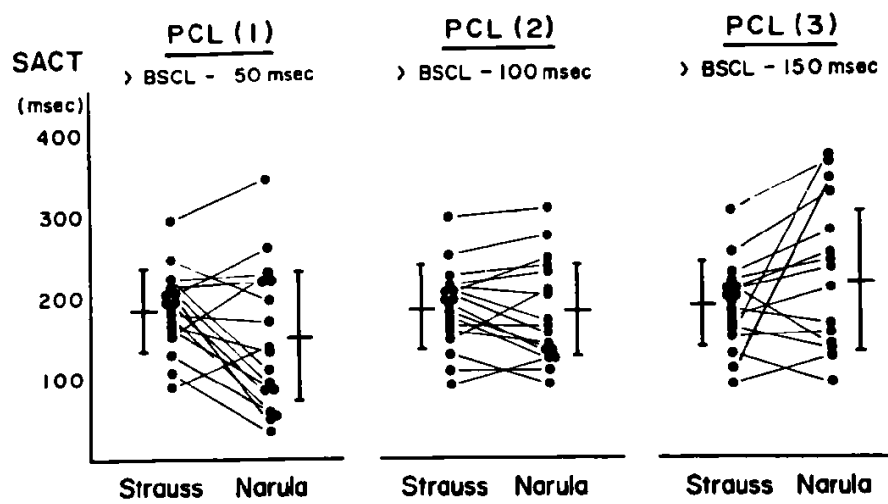

Fig. 2. The sinoatrial conduction times (SACTs) by the Strauss method are compared with the SACTs by the Narula method in each three pacing cycle length.
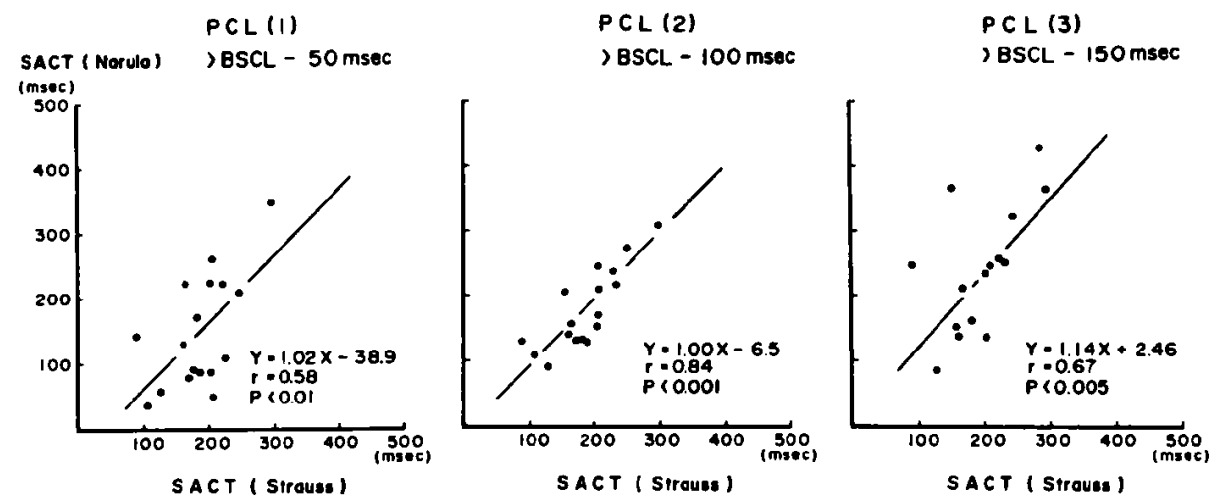

Fig. 3. The correlation of the sinoatrial conduction times (SACTs) by the Strauss method and the Narula method in each pacing cycle length (PCL). The best coefficient of correlation is $r=0.84$ at PCL (2). The line represents the line of regression.

PCL.

In Fig. 2, the SACT by the Narula method at the three PCLs were compared with the SACT by the Strauss method for group A. The mean SACT at PCL(1) (147.6 $\pm 80.7 \mathrm{msec})$ was shorter than the mean SACT by the Strauss method $(184.7 \pm 49.5 \mathrm{msec})$, and showed that for most patients, each SACT by the Narula method was shorter than the SACT by the Strauss method.

On the other hand, the mean SACT at PCL(2) was $180.9 \pm 58.7 \mathrm{msec}$ and each SACT showed good correspondence with the SACT by the Strauss method. However, at PCL(3), in most cases (11/15), the SACT was greater than the SACT by the Strauss method. The correlation of both methods 


\section{PAS Method (Strauss)}

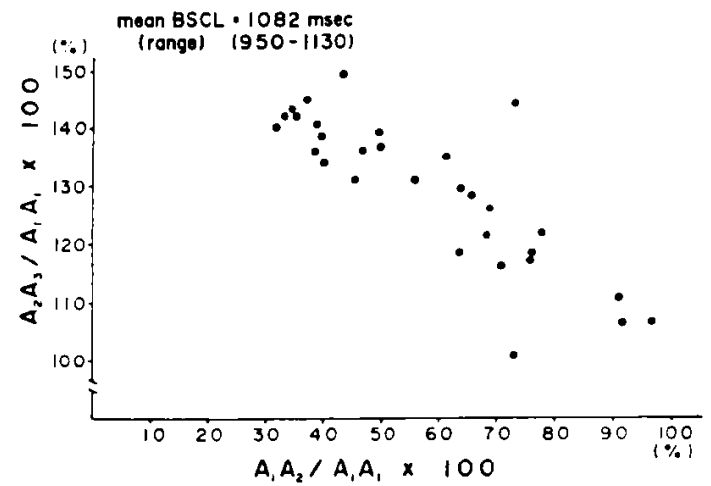

\section{CAP Method ( Narula)}

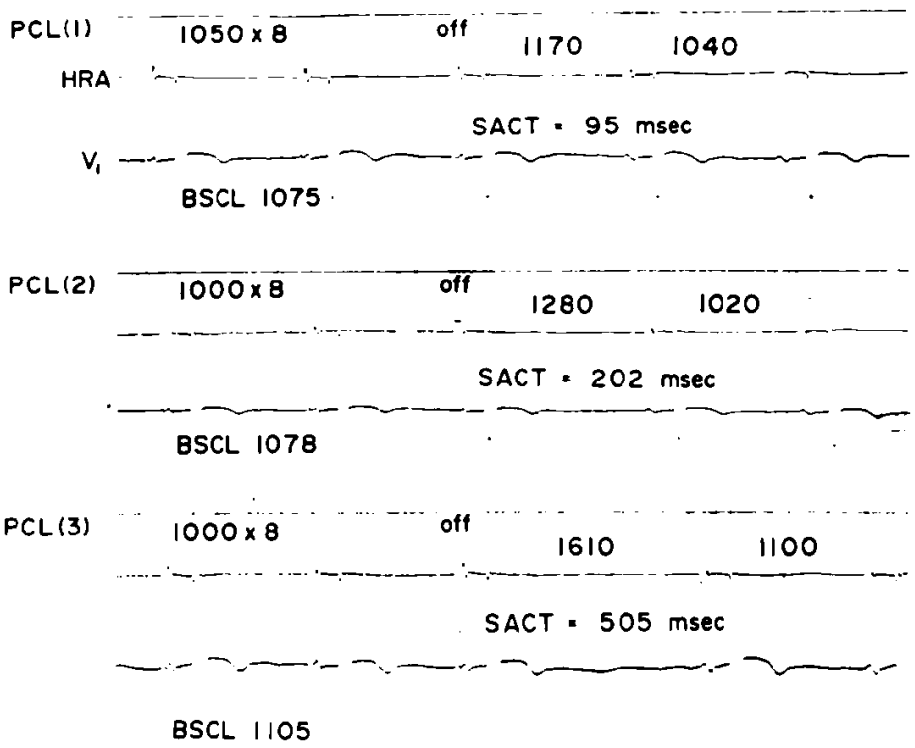

Fig. 4. The upper panel shows a case of atypical $1^{\circ} \mathrm{SA}$ block in which sinoatrial conduction time (SACT) could not be estimated by the Strauss method because of no reset responses of the atrial return cycles. In the lower panel, the SACTs obtained by the Narula method, show a gradual increase from $95 \mathrm{msec}$ to $505 \mathrm{msec}$ as the pacing cycle length (PCL) is shortened.

was shown in Fig. 3. At PCL(2), $\mathrm{Y}=1.00 \mathrm{X}-6.5$ was obtained, and the coefficient of correlation was 0.84 . The most proper pacing cycle length was identified as PCL(2).

In group B, 3 patients with SA block (case nos. 20, 22, and 24) showed a "chaotic pattern" of the atrial return cycles, and the SACT could not be calculated. For case no. 26 (66-year-old, female, bradycardia-tachycardia 

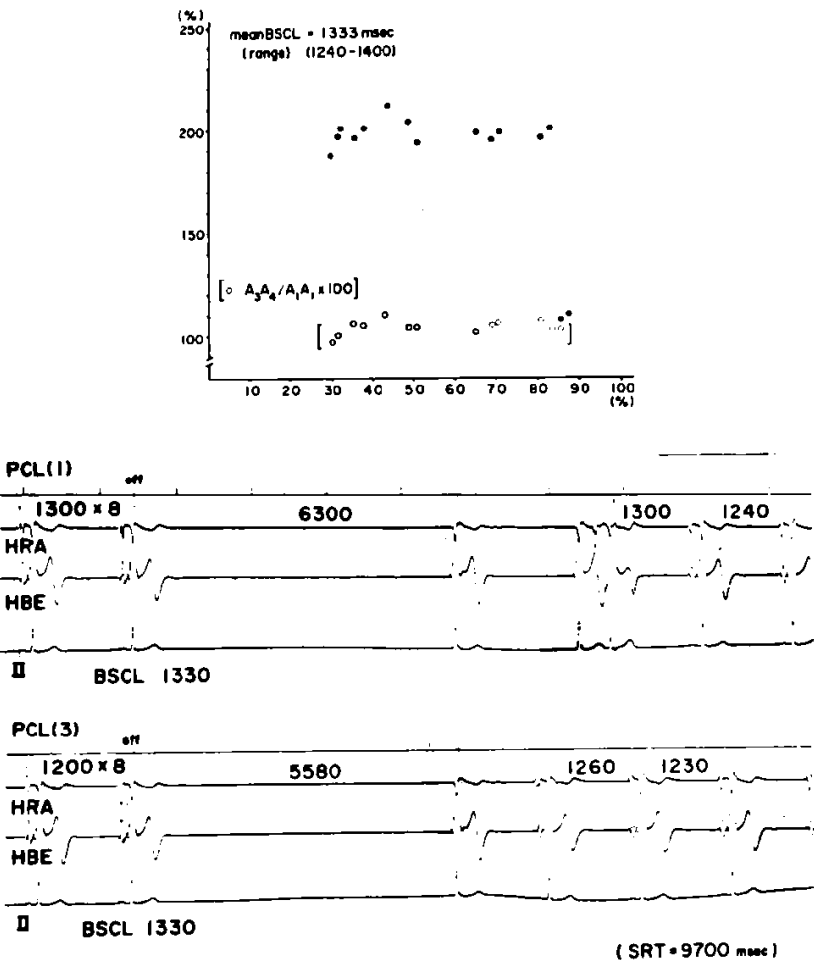

Fig. 5. A case of spontaneous 2: 1 SA block that shows the atrial return cycles near the $200 \%$ line (closed circles) and the post atrial return cycles near the $100^{\circ}$ line (open circles) by the Strauss method in the upper panel. By the Narula method in the lower panel, the marked prolongation of the atrial return cycles is shown after each pacing. The sinus node recovery time (SRT) is $9,700 \mathrm{msec}$.

Syndrome), both methods were shown in Fig. 4. By the Strauss method, the atrial return cycles were less than compensatory, and the Zone II was nondefinable. This case was diagnosed as atypical $1^{\circ} \mathrm{SA}$ block or Type $\mathrm{B}_{2}$ response by Ueda et al. ${ }^{12}$ ) On the other hand, by the Narula method, the estimated SACT was $95 \mathrm{msec}$ at PCL(1), $202 \mathrm{msec}$ at PCL(2), and 505 msec at PCL(3), respectively. These SACTs showed a gradual increase as the PCL was shortened, and the SACTs were dispersed from $158 \mathrm{msec}$ to $318 \mathrm{msec}$ even at the same PCL(2). In this case, whose SACT could not be determined by the Strauss method, it was uncertain if the dispersed SACTs obtained by the Narula method indicated the true SACT.

Fig. 5 showed another example of a patient (case no. 21, 47-year-old, male) who showed spontaneous 2:1 SA block on the standard ECG. Atrial return cycles were plotted in the vicinity of the $200 \%$ line on the ordinate, and post return cycles were near the $100 \%$ line. The prolongation of the 
atrial return cycle was considered due not to the sinus node suppression but to $2^{\circ} \mathrm{SA}$ block (SA exit block). By the Narula method, even PGL(1) of $1300 \mathrm{msec}$ at BSCL $1330 \mathrm{msec}$ showed marked prolongation of the first HRA excitation after the pacing. Markedly delayed HRA activity (6300 msec) captured a ventricular complex with aberrant conduction. Marked prolongation of HRA recovery also occurred at PCL(3) of $1200 \mathrm{msec}$. In this case, sinus node overdrive suppression may be the most likely reason for the prolongation of the HRA recovery. Because of the marked prolongation of the SACTs by the Narula method, the case was deleted from the statistical analysis.

\section{Discussion}

Recently, studies on the isolated tissues have demonstrated many problems in using premature atrial stimulation to estimate SACT. ${ }^{5), 6)}$ Strauss et al also pointed out ${ }^{10}$ that this method is burdened with many inherent problems insofar as it uses an extrastimulus to estimate SACT: (1) the action potential duration of the sinus node may be shortened, (2) the sinus node automaticity may be depressed, (3) shifting of the pacemaker may occur, (4) the antegrade and retrograde conduction times are different, (5) a special programmable stimulator is required, (6) a large number of cumbersome measurements and calculations are necessary to define Zone II, and (7) in $20-30 \%$ of the cases, SACT could not be estimated according to the recent reports. ${ }^{7}$

Meanwhile, Narula et al proposed a new method of estimation of SACT using continuous atrial pacing. They reported that this method is simpler and quicker, and it is performed not by a programmable stimulator but by an ordinary temporary pacemaker, and that the SACT by the method corresponded very well with the SACT by the Strauss method.

We were very intersted in their report because Narula et al showed that in 2 cases of SA block, the SACT could be calculated by their method. Using the Strauss method, however, it could not be estimated because the $\mathrm{A}_{2} \mathrm{~A}_{3}$ responses after the premature atrial stimulation were fully compensatory.

In patients with normal sinus node function, this new method is very useful as shown by our results. However, a report by Breithardt and Seipel was skeptical of the reliability of the results obtained with the Narula method. ${ }^{13)}$ We thought that the pacing rates used by Breithardt and Seipel might be the origin of the negative data. They used rates that were 3 beats/ min faster than the spontaneous sinus rate for only 8-10 paced cycles. In about $30 \%$ of their cases, the SACT by both methods coincided well, 
Table II. The Proper Pacing Rate for Estimation of SAGT by the Narula Method

\begin{tabular}{c|c}
\hline Heart & Pacing Rate \\
\hline 50 & $-52-55$ \\
60 & $63-67$ \\
70 & $74-79$ \\
80 & $86-92$ \\
90 & $97-106$
\end{tabular}

Footnotes: Heart = the heart rate of the patients; Pacing Rate=the pacing rate for estimation of SACT properly.

but in the rest of the patients the SACT by the Narula method was shorter than the SACT by the Strauss method. They showed that the coefficient of correlation was $r=0.45$. Their explanations for the result were as follows: (1) single premature stimulation may suppress the automaticity of the sinus node greater than continuous atrial pacing, (2) retrograde conduction time is longer by the premature atrial stimulation method, and (3) overdrive excitation of the sinus node may occur when using the continuous atrial pacing method.

We used almost the same pacing rates for $\operatorname{PCL}(1)$ as that used by Breithardt and Seipel, and we also obtained a poor correlation $(r=0.58)$ between both methods at this rate. The most acceptable explanation for these results may be that the atrial or sinus node capture was insufficient at these pacing cycle lengths. The SACT by the Narula method is mainly dependent on the pacing rate which is shown by our results and by those of Grant et al. ${ }^{11}$ We showed $\mathrm{r}=0.84$ at PCL(2) in patients with normal sinus node function, and we considered this PCL as the most proper pacing rate for estimation of SACT by the Narula method. The patients should be examined at the proper pacing cycle length (PCL(2)) which was translated into the number of the heart beats/min in Table II.

On the other hand, we were not able to achieve greater success with the Narula method as compared with the Strauss method in patients with sinus node dysfunction. In our case (no. 26) shown in Fig. 4, atypical $1^{\circ}$ SA block or Type $\mathrm{B}_{2}$ response by the criteria of Ueda et al was diagnosed because the atrial return cycles were less than compensatory and SACTs were gradually prolonged. This type of response was frequently observed in aged patients notwithstanding the presense or absence of clinical presentation of sinus node dysfunction in their report. ${ }^{12}$ ) Ueda et al suggested that the fact might imply that electrophysiological properties of the sinus node or peri-nodal fiber were frequently impaired in aged patients with other types of conduction disturbances. 
Narula showed in 1 of the 2 cases that atrial return cycles were fully compensatory, as a typical example which could be calculated easily by their method in their Figs. 4 and 5. In their Fig. 5, the atrial pacing at a cycle length of $700 \mathrm{msec}$ ( 86 beats/min) was applied when the mean BSCL was $800 \mathrm{msec}$ ( 75 beats/min). They showed the estimated SACT as $310 \mathrm{msec}$ and $330 \mathrm{msec}$ although the PCL is more than 10 beats/min faster than the BSCL. But the estimated SACTs by shorter pacing cycles showed a prolonged SACT in their Table I. We think that the estimated SACT by the PCL 700 msec may correspond with the SACT at the middle portion of the slope (compensatory line). Our study suggested that the Narula method may risk estimating the SACT improperly if only one pacing cycle length is applied to the patients such as our case no. 26 .

Another case of SA block (case no. 25) showed abnormally prolonged atrial return cycles by $\mathrm{PCL}(1)$ which was slightly shorter than the BSCL. In this case, the automaticity of the sinus node was abnormally suppressed by the continuous atrial pacing, however, the premature atrial stimulation showed 2:1 SA block and no effect on the automaticity. Grant et al11) suggested that it seemed likely that pacing for more than a single beat would depress sinus node automaticity to the same extent or an even greater extent.

In group B, 5 of the 8 cases $(63 \%$ ) showed prolonged SACT (over 215 msec) even at PCL(2) and all of the 8 cases (100\%) did at PCL(3). These results may be due to the overdrive sinus node suppression or partly due to prolongation of the SACT. Although mean SACTs by each PCLs were calculated arithmetically and shown in Table $\mathrm{I}$, we sometimes felt that it was misleading to present the data because the differences of calculated SACTs in same PCL $(20-200 \mathrm{msec})$ were so great in each patient.

Our results suggest that more attention should be paid when the Narula method is tried in such patients, although the method would be applicable to the patients of $1^{\circ}$ SA block theoretically, because of the two reasons: (1) the atrial return cycles were abnormally prolonged and scattered even at PCL(2), for impaired sinus node automaticity is often combined in such patients, and (2) the SACT may be estimated improperly if only one PCL was applied to the patients of $1^{\circ} \mathrm{SA}$ block. For these reasons, several PCLs should be tried to avoid such an error when this method is applied to estimate SACT in patients with sinus node dysfunction.

On the other hand, by the Strauss method, only 2 patients clearly showed a definite Zone II, but in the other cases, 1 patient showed atypical $1^{\circ}$ SA block or Type $B_{2}$ response of the atrial return cycles by Ueda et al, 2 patient showed $2^{\circ} \mathrm{SA}$ block (SA exit block) and 3 patients showed " chaotic pattern". 
The significance of SACT is still controversial. Some investigators reported that the estimation of SACT is useful to differentiate patients with sinus node dysfunction from patients with normal sinus node function. ${ }^{10,14,15}$ ) Other investigators concluded from their results that programmed atrial stimulation is not of great clinical value. ${ }^{12), 16), 17)}$ However, most authors still believe, although the Strauss method has many problems and the limitations, that this method is currently the best available for characterization of sinoatrial conduction. And now it is potentially possible to differentiate the abnormal sinus node automaticity and impaired impulse conduction through peri-nodal fibers despite the fact that the differentiation is sometimes difficult because these abnormalities are occasionally combined.

In conclusion, when proper PCL (in Table II) is used to determine the SAGT by the Narula method in patients with normal sinus node function, the SACTs by both methods correlate very well. However, it is difficult to determine SACT in patients with sinus node dysfunction by both methods.

We hope that this simple method will prove to be useful in many catheterization laboratories where SACT estimation has never been tried because of the problems of the Strauss method, and that the clinical and electrophysiological aspects of the SACT will be discussed more and more as they relate to the evaluation of the sinus node function.

\section{ACKNOWLEDGMENT}

The authors gratefully acknowledge Prof. Achilles J. Pappano, Department of Pharmacology, University of Connecticut Health Center, for helpful criticism and comments.

\section{REFERENGES}

1. Reiffel J, Gliklick J, Gang E, Weiss M, Davis J, Bigger JT Jr: Human sinus node electrograms. Transvenous catheter recorded technique and normal sinoatrial conduction time in adults. Girculation 59 (Suppl II): II-63, 1979

2. Reiffel J, Gliklick J, Gang E, Weiss M, Davis J, Bigger JT Jr: Comparison of directly recorded and indirectly estimated sinoatrial conduction time. Circulation 59 (Suppl II): II-63, 1979

3. Hariman RJ, Krongrad E, Boxer RA, Weiss MB, Steeg CN, Hoffman BF: Method for recording electrical activity of the human sinoatrial node and automatic atrial foci during cardiac catheterization in human subjects. Am J Cardiol 45: 775, 1980

4. Hariman RJ, Krongrad E, Boxer RA, Bowman FO Jr, Malm JR, Hoffman BF: Methods for recording electrograms of the sinoatrial node during cardiac surgery in man. Circulation 61 : 1024,1980

5. Strauss HC, Saroff AL, Bigger JT Jr, Giardina EGV: Premature atrial stimulation as a key to the understanding of sinoatrial conduction in man. Circulation 47: 86, 1973

6. Strauss HC, Wallace AG: Direct and indirect techniques in the evaluation of sinus node function. in The Conduction System of the Heart, ed by Wellens HJJ, Lie KI, Janse MJ, 
Leiden HE, Lea \& Febiger, Philadelphia, p. 227, 1976

7. Breithardt G, Seipel L: The effect of premature atrial depolarization on sinus node automaticity in man. Circulation 53: 920,1976

8. Narula OS, Shantha N, Vasquez M, Towne WD, Linhart JW: A new method for measurement of sinoatrial conduction time. Circulation 58: 706, 1978

9. Scherlag BJ, Lau SH, Helfant RH, Berkowitz WD, Stein E, Damato AN: Catheter technique for recording $H$ is bundle activity in man. Circulation 39: 13, 1969

10. Strauss HC, Bigger JT Jr, Saroff AL, Giardina EGV: Electrophysiologic evaluation of sinus node function in patients with sinus node dysfunction. Circulation 53: 763, 1976

11. Grant AO, Kirkorian G, Benditt DG, Strauss HC: The estimation of sinoatrial conduction time in rabbit heart by the constant atrial pacing technique. Circulation 60: 597. 1979

12. Ueda K, Kamata C, Matsuo H, Ohkawa S, Okimoto T, Sugiura M: A study on sinoatrial conduction in the aged. Jpn Heart J 18: 143, 1977

13. Breithardt G, Seipel L: Comparative study of two methods of estimating sinoatrial conduction time in man. Am J Cardiol 42: 965, 1978

14. Breithardt G, Seipel L, Loogen F: Sinus node recovery time and calculated sinoatrial conduction time in normal subjects and patients with sinus node dysfunction. Circulation 56: 43, 1977

15. Jordan J, Yamaguchi I, Mandel WJ: Characteristics of sinoatrial conduction in patients with coronary artery disease. Circulation 55: 569, 1977

16. Crook B, Kiston D, McComish M, Jewitt D: Indirect measurement of sinoatrial conduction time in patients with sinoatrial disease. Brit Heart $\mathrm{J}$ 39: 771, 1977

17. Dhingra RC, Amat-y-Leon F, Wyndham C, Deedwania PG, Wu D, Denes P, Rosen KM: Clinical significance of prolonged sinoatrial conduction time. Circulation 55: 8, 1977 